\title{
A COMPUTATIONAL MODEL OF THE INITIAL/PRE-COLLECTING LYMPHATICS, AND A STUDY OF LYMPHATIC VALVOGENESIS
}

\author{
BERNARD OSAYIMWENSE IKHIMWIN (D)
}

(Received 9 November 2020; first published online 18 January 2021)

2020 Mathematics subject classification: primary 92B05; secondary 92C15.

Keywords and phrases: fluid flow, lymphatics, valvogenesis.

This thesis describes a computational model for an initial/pre-collecting lymphatic network and a study on valvogenesis (formation of valves in the lymphatics during embryonic development). The computational model was applied to rat mesenteric lymphatic networks (19- and 163-segment) with sparse secondary valves. The network was simulated with these secondary valves being operational and nonoperational. Sensitivity of parameters, such as the vessel stiffness, interstitial resistance and the availability of primary valves, on the cycle-mean outflow rate from the 19-segment network was considered. Results for the study on valvogenesis, simulations done on 2D images of the embryonic skin lymphatic network, suggest that fluid shear stress does not localise the expression of Prox1 (a transcription factor responsible for valve formation).

Some of this research has been published in $[1,2]$.

\section{References}

[1] B. O. Ikhimwin, C. D. Bertram, S. Jamalian and C. Macaskill, 'A computational model of a network of initial lymphatics and pre-collectors with permeable interstitium', Biomech. Model. Mechanobiol. 19(2) (2020), 661-676.

[2] B. O. Ikhimwin, C. D. Bertram, S. Jamalian and C. Macaskill, 'Correction to: "A computational model of a network of initial lymphatics and pre-collectors with permeable interstitium", Biomech. Model. Mechanobiol. 19(2) (2020), 677-679.

BERNARD OSAYIMWENSE IKHIMWIN, School of Mathematics and Statistics, University of Sydney, Camperdown, New South Wales 2006, Australia e-mail: bikh5855@uni.sydney.edu.au

Thesis submitted to the University of Sydney in March 2020; degree approved on 15 July 2020; supervisor Mary Myerscough, auxiliary supervisor Christopher Bertram.

(C) 2021 Australian Mathematical Publishing Association Inc. 